\title{
Analysis of Mad Honey (Grayanotoksin) Cases Admitted to Duzce University School of Medicine Emergency Department
}

\author{
Ahmet Tekinsoy ${ }^{1}$, Seher Orbay Yasli2*, Ayhan Saritas ${ }^{3}$, Harun Gunes ${ }^{3}$, Ertugrul Kaya ${ }^{4}$, \\ Feruza Turan Sonmez ${ }^{3}$ \\ ${ }^{1}$ Emergency Service, Ömer Halis Demir Training Research Hospital Medicine, Nigde, Turkey \\ ${ }^{2}$ Division of Anesthesiology, Kaman State Hospital, Kirsehir, Turkey \\ ${ }^{3}$ Emergency Service, Duzce Medical Faculty, Duzce, Turkey \\ ${ }^{4}$ Department of Pharmacology, Duzce Medical Faculty, Nigde, Turkey \\ Email: doctorahmet2017@hotmail.com, ^syasli@erciyes.edu.tr, a_saritas@hotmail.com, haroonsun@hotmail.com, \\ drekaya@yahoo.com, feruzaturan@yahoo.com
}

How to cite this paper: Tekinsoy, A., Yasli, S.O., Saritas, A., Gunes, H., Kaya, E. and Sonmez, F.T. (2017) Analysis of Mad Honey (Grayanotoksin) Cases Admitted to Duzce University School of Medicine Emergency Department. Open Journal of Emergency Medicine, 5, 13-24.

https://doi.org/10.4236/ojem.2017.51003

Received: March 8, 2017

Accepted: March 27, 2017

Published: March 30, 2017

Copyright $\odot 2017$ by authors and Scientific Research Publishing Inc. This work is licensed under the Creative Commons Attribution International License (CC BY 4.0).

http://creativecommons.org/licenses/by/4.0/

\begin{abstract}
Background: Mad honey is the type of honey made by bees that are nourished from the plants of Rhododendron (Rh.) family, and it contains grayanotoksin (GTX). The most significant types of Rh family, which contain GTX, are Rh. The purpose of this study was to analyze the cases which came to the emergency room because of GTX intoxication in detail in order to help diagnosis, treatment, follow-up and prognosis in daily emergency medicine practice. A total of 36 patients with the symptoms and diagnosis of intoxication after consuming mad honey, were included in the study. Ten healthy individuals who did not have a history of taking mad honey were included in the control group. The study is designed as a prospective case control study. The average GTX level of the group who ate mad honey (studygroup) was $7.88 \mathrm{ng} / \mathrm{ml}$ (min: $0.00 / \max : 30.47$ ). At control group, GTX level was $0 \mathrm{ng} / \mathrm{ml}$. There was no statistically significant relationship between the symptoms (dizziness, nausea, vomiting, weakness, deterioration, angina) and blood GTX level in the study group. Also statistic value reflects relationship between kidney function tests, troponin and control troponin levels in case group. The patients who have absolute decrease in blood pressure and pulse should be questioned by emergency medicine doctors about consuming mad honey. Further studies are needed to demonstrate the relationship between symptoms and GTX poisoning.
\end{abstract}

\section{Keywords}

Grayanotoxin, Mad Honey, Rhododendron 


\section{Introduction}

Mad Honey is the name given to honey containing grayanotoxin (GTX) produced by bees fed from Rhododendron (Rh) family plants. The Rh family, which is common in Turkey, has more than 750 species in various regions of the world such as Spain, Portugal, Japan and Brazil [1]. The most important species of Rh family containing GTX are Rh ponticum and Rh flavum, which are found in the sea-facing parts of the mountains extending along the Black Sea coast in Turkey. These plants usually bloom in late May and early June. The rate of GTX in these plants varies depending on whether the weather is rainy or not when the plants are blooming. During periods when rain is low, the GTX ratio is high and this increases the likelihood of honey poisoning [2].

Poisoning due to GTX can lead to loss of consciousness, relaxation in the muscles; and can result in death due to significant blood pressure and the drop in pulse. GTXs show these toxic effects by binding to sodium channels in cell membranes [3].

Mad honey is used as an alternative medicine agent in many parts of the world, especially in the Black Sea region of Turkey. Mad honey is preferred as it is effective as an appetite enhancer and a sexual stamina. In addition, due to blood pressure lowering effects it is used for patients with hypertension, due to sedative effects used for patients with depression; and used as an alternative medicine for joint pain and gastrointestinal system pain [4] [5]. It is estimated that middle-aged and elderly male patients use mad honey more because of the sexual power-enhancing effect.

There are numerous studies in the literature about GTX-related poisonings [4]-[12]. However, there are not enough studies showing the relationship between GTX dose and symptoms.

\subsection{Clinical Results}

GTX poisoning is a toxic effect in most people eating mad honey. The most common signs of poisoning are severe hypotension and bradycardia [13]. Other symptoms other than these findings are sweating, dizziness, mental status change, syncope, diplopia, blurred vision and hypersalivation [14].

Again, the honey eating person has a feeling of burning in the skin and throat, itching in the mouth and the back, redness in the eyes and deep, vertigo and headache, nausea, vomiting, salivation, cramp abdominal pain, urinary and gait incontinence, gastroenteritis, or temporary blindness, febrile seizures resembling malaria, deep bradycardia, hypotension and delirium can be seen [14].

Non-specific bradyarrhythmias or sinus bradycardias are frequently seen in GTX poisonings. In addition, different degrees of heart block, nodal rhythm, AV Full block and second degree heart block can be seen. Asystole and Wolff-Parkinson-White syndrome were also observed in several cases of GTX poisonings [4]. Poisoning-induced hypotension and bradycardia can cause myocardial infarction due to slowing of the coronary flow [15].

Depending on the dose, all kinds of rhythm disturbances (sinus bradycardia, 
AV block, T sharpness, ST changes) similar to digoxin poisoning, respiratory depression and muscle paralysis can be seen in mad honey poisonings. Mad honey intoxication is a syndrome that should be considered in the differential diagnosis of acute myocardial infarction and acute bradyartimas [9].

The average amount of honey taken from GTX poisonings is generally between 5 and $30 \mathrm{~g}$. Symptoms start within 1.5 to 3 hours after eating honey [1]. Poisoned patients usually return to their original state with adequate saline supportive therapy and $1-2 \mathrm{mg}$ intravenous atropine. Patients can be discharged after 2 to 6 hours of cardiac monitoring in mild poisonings. Significant symptoms and signs usually disappear within 24 hours in untreated serious poisonings. During this period, most vital signs return to normal in most patients [16].

\subsection{Diagnosis}

In the presence of life-threatening clinical findings such as bradycardia, hypotension, vomiting, diarrhea and delirium, the story of eating honey must be questioned [13]. Chromatography is the most important method for definitive diagnosis, but other methods are used because it cannot be done everywhere [10]. One of the methods used for this purpose is to observe the toxic effect by giving the toxic honey to the subject. Another method is to search for flower dust in the honey. The GTX level can also be determined from biological samples by Liquid Chromatography Mass Spectrometry/Mass Spectrometry (LCMS/MS) method.

\subsection{Treatment}

In GTX-related intoxications, symptoms disappear within 12 to 24 hours before treatment is achieved in severe cases [17]. Supportive and symptomatic treatment is applied to severe poisonings that occur after excessive ingestion of honey.

If necessary, $0.9 \%$ sodium chloride solution should be given intravenously (IV) for fluid electrolyte losses. If salivation, reflex hypotension, bradycardia are present; atropine should be given [5].

If hyperexcitability and delirium are present, sedatives may be administered intramuscularly with chlorpromazine 25 to $50 \mathrm{mg}$. If cyanosis is present, $\mathrm{O}_{2}$ support; if severe respiratory depression is present, mechanical ventilation may be required. Sympathomimetics may be given if severe hypotension is present, but this should be treated with extreme caution [18] [19] [20].

These treatments ensure that most of the poisoned patients recover vital signs within the first 24 hours. However, in the literature, it has been shown that there are patients that requires pacemaker, cardiopulmonary resuscitation with advanced life support. In addition, in 1853 Coleman's work reported deaths [8].

Despite the need for monitoring and treatment of intensive care unit conditions in a small proportion of cases of GTX poisoning, cases followed in internal medicine services are also important in terms of work loss and bed occupation ( 2 - 3 days in hospital).

There is no complete consensus on how long patients should be kept under 
observation in the hospital for patients who are diagnosed with mad honey poisoning. However, Gündüz et al. proposed two different studies to discharge these patients after 2 - 6 hours of observation [14] [21].

\section{Methods}

This study was conducted as a prospective case control study in Düzce University Emergency Medicine Department. Research has been ethically and scientifically approved by the board decision of Düzce University Clinical Research Ethics Committee dated 13.01.2015 numbered 2014/92. 36 cases, who applied to the emergency department with symptoms and findings of mad honey ingestion between March 1 $1^{\text {st }}, 2015$ and March 1 ${ }^{\text {st }}, 2016$, were included in our study. Our study which is planned as a prospective controlled case study, 10 patients, who applied to Düzce University Research and Practice Hospital Emergency Service between the dates March 1 ${ }^{\text {st }}, 2015$ and March $1^{\text {st }}, 2016$ without the ingestion story of mad honey in the near time, were included as a control group.

Patients who applied to Düzce University Research and Practice Hospital Emergency Service and started symptoms likenausea, dizziness, fatigue, exhaustion, throat burns, vomiting, or abdominal pain shortly after eating mad honey were included in the study. For the control group, patients who applied to our emergency department during the study period and who did not have a recent story of mad honey eating were included. Patients under 18 years of age, patients who became ill after eating honey but whose clinical findings were incompatible with GTX poisoning, patients without informed consent or whose consent could not be obtained were excluded from the study.

Demographic information, complaints, anamnesis and physical examination findings, vital findings, entrance-leaving (to and from hospital) EKGs of the patients, type of the ingested honey, the ingested amount, time how long ago it was ingested, the purpose of ingestion, drugs used by the patients, Glasgow coma scale (GKS) value, studied blood tests (Glucose, urea, BUN, creatinine, CK, $\mathrm{CKMB}$, Troponin) results etc. have been recorded. The study group was followed up for 6 hours in emergency department and control troponin was taken at the end of 6 hours.

GTX level and baseline biochemical values were examined in $6 \mathrm{cc}$ venous blood samples taken from patients. Blood samples were centrifuged in NF 048 (Microlitre and Hematocrit Centrifugal Nüve Industrial Materials Manufacturing Co. 2008) for $10 \mathrm{~min}$ at $4000 \mathrm{rpm}$ at room temperature in a biochemical tube. Each serum obtained was stored at $-20^{\circ} \mathrm{C}$ after the procedure. The stored materials were analyzed at Liquid Chromatography Mass Spectrometry/Mass Spectrometry (LC-MS/MS) device at the end of the study period to determine GTX levels.LC-MS/MS technique; sample molecules separated according to their physicochemical properties are analyzed by Mass Detector thanks to High Performance Liquid Chromatography (UPLC) device. Molecules are normally not charged particles, and mass spectrometers convert ions into charged ionic molecules by ionizing the molecules. In the first quadrupole filter, the molecules 
separated according to the $\mathrm{m} / \mathrm{z}$ (mass/charge) ratio are subjected to fragmentation with a special gas of high purity called collision gas. The second quadrupole filter is diagnosed and quantitated through the ions formed as a result of fragmentation. Although there are many molecules with the same $\mathrm{m} / \mathrm{z}$ ratio, the number of molecules with the same cleavage ion is $1 / 10,000$ in nature. For this reason, LC-MS/MS makes it possible to quantify the substance at very low concentrations.

\section{Statistical Analysis}

Analysis of the data obtained from the survey was performed using the SPSS for Windows (v21.0) package program. The Shapiro-Wilk test was used for the variables with normal distribution suitability of $\mathrm{n} \leq 50$. For normal numeric variables, descriptive statistic is taken as mean \pm standard deviation, normal distribution is median for non-fit variables, and frequency tables for qualitative variables with minimum-maximum values.

Statistical comparisons of two or more unsuitable groups with normal distribution were performed using the Kruskal Wallis- $\mathrm{H}$ test. The significance of the difference between two variables without normal distribution was tested with Mann Whitney-U. The mean difference between two normal distributions was analyzed by t-test. The level of error was selected as $\alpha=0.05$ for all statistical evaluations. These values are interpreted as "statistically significant different" for equal or smaller values.

\section{Results}

When the age distribution of patients in our study group was examined, the mean age of the patients was $58.11 \pm 13.92$. The mean age of the control group was $53.0 \pm 14.97$ (Table 1 ).

GTX levels were found to be statistically significant in the case group compared to the control group (Table 2).

In the case group (Table 3), there was no significant difference between the GTX level of patients with symptoms (dizziness, nausea, vomiting, fatigue, and throat burning) and the GTX level of patients without these symptoms.

Table 1. Gender and age distribution in case and control groups.

\begin{tabular}{cccc}
\hline Patient Group & Number/Gender & Age (Avg) & Min/Max Age \\
\hline Case Group & $36 / 9 \mathrm{~F}(\% 25), 27 \mathrm{M} \mathrm{( \% 75)}$ & $58.1 \pm 13.92$ & $25 / 90$ \\
Control Group & $10 / 8 \mathrm{~F}(\% 80), 2 \mathrm{M}(\% 20)$ & $53.0 \pm 14.97$ & $36 / 80$ \\
\hline
\end{tabular}

Min: Minimum, Max: Maximum, F: Female, M: Male, Avg: Average.

Table 2. Distribution of grayanotoxin levels (median) in case and control groups.

\begin{tabular}{cccc}
\hline GTX (ng/ml) & Case Group (n:36) & Control group (n:10) & $\mathrm{p}$ \\
\hline Average level & 7.88 & 0.00 & \\
Standard Deviation & 6.80 & 0.00 & $\mathrm{p}<0.001$ \\
Minimum level & 0.00 & 0.00 & \\
Maximum level & 30.47 & 0.00 & \\
\hline
\end{tabular}


Table 3. Symptoms of a patient eating mad honey.

\begin{tabular}{cc}
\hline Symptoms & $\mathbf{n}$ \\
\hline Nausea & $27(\% 75.0)$ \\
Dizziness & $25(\% 69.4)$ \\
Fatigue & $20(\% 55.6)$ \\
Exhaustion & $19(\% 52.8)$ \\
Vomit & $18(\% 50.0)$ \\
Throat Burns & $6(\% 16.7)$ \\
Abdominal pain & $1(\% 2.8)$ \\
\hline
\end{tabular}

Table 4. Relationship between renal function tests and cardiac biomarkers in the case group.

\begin{tabular}{cccccc}
\hline & & $\mathrm{CK}(\mathrm{U} / \mathrm{L})$ & $\mathrm{CKMB}(\mathrm{U} / \mathrm{L})$ & $\begin{array}{c}\text { Troponin } \\
(\mathrm{ng} / \mathrm{mL})\end{array}$ & $\begin{array}{c}\text { Control Troponin } \\
(\mathrm{ng} / \mathrm{mL})\end{array}$ \\
\hline Urea $(\mathrm{mg} / \mathrm{dL})$ & $\mathbf{r}$ & 0.031 & -0.012 & $\mathbf{0 . 4 3 8}$ & $\mathbf{0 . 4 5 3}$ \\
& $\mathrm{p}$ & 0.855 & 0.943 & $\mathbf{0 . 0 0 8}$ & $\mathbf{0 . 0 0 6}$ \\
BUN (mg/dL) & r & 0.052 & 0.028 & $\mathbf{0 . 3 9 2}$ & $\mathbf{0 . 4 9 4}$ \\
& $\mathrm{p}$ & 0.763 & 0.871 & $\mathbf{0 . 0 1 8}$ & $\mathbf{0 . 0 0 2}$ \\
Creatinine (mg/dL) & $\mathbf{r}$ & -0.115 & -0.193 & 0.320 & $\mathbf{0 . 3 6 9}$ \\
& $\mathrm{p}$ & 0.505 & 0.259 & 0.057 & $\mathbf{0 . 0 2 7}$ \\
\hline
\end{tabular}

Positive (linear) significant relationships between urea and troponin $(\mathrm{r}=$ $0.438, \mathrm{p}=0.008)$ and control troponin $(\mathrm{r}=0.453, \mathrm{p}=0.006)$ were found in the case group. There was a linear relationship between BUN and troponin $(\mathrm{r}=$ $0.392, \mathrm{p}=0.018)$ and control troponin $(\mathrm{r}=0.494, \mathrm{p}=0.002)$. Positive (linear) significant relationships were also found between creatinine and control tropo$\operatorname{nin}(\mathrm{r}=0.369, \mathrm{p}=0.027)($ Table 4$)$.

Hospital entrance EKGs of the study group; among 36 patients; 1 patient had anterior MI, 19 had sinus bradycardia, 1 had Ventricular Tachycardia, and 15 had Normal Sinus Rhythm. Examination of the hospital-leaving EKGs revealed that all of the 36 patients were in normal sinus rhythm (Figure 1).

There was no significant difference between the amount of honey taken by patients with symptoms of dizziness, nausea, vomiting, fatigue, and throat burns and the amount of honey taken by patients without these symptoms. There was no significant difference between symptoms and the time how long ago the mad honey was taken.

\section{Discussion}

Mad honey poisoning occurs when honey, which is eaten by bees from Rhododendron flowers, is consumed. This toxicity is caused by the presence of GTX in honey. Nowadays mad honey is mostly used as an alternative medicine agent. Taking more than a teaspoon of this honey can cause poisoning findings [1]. 


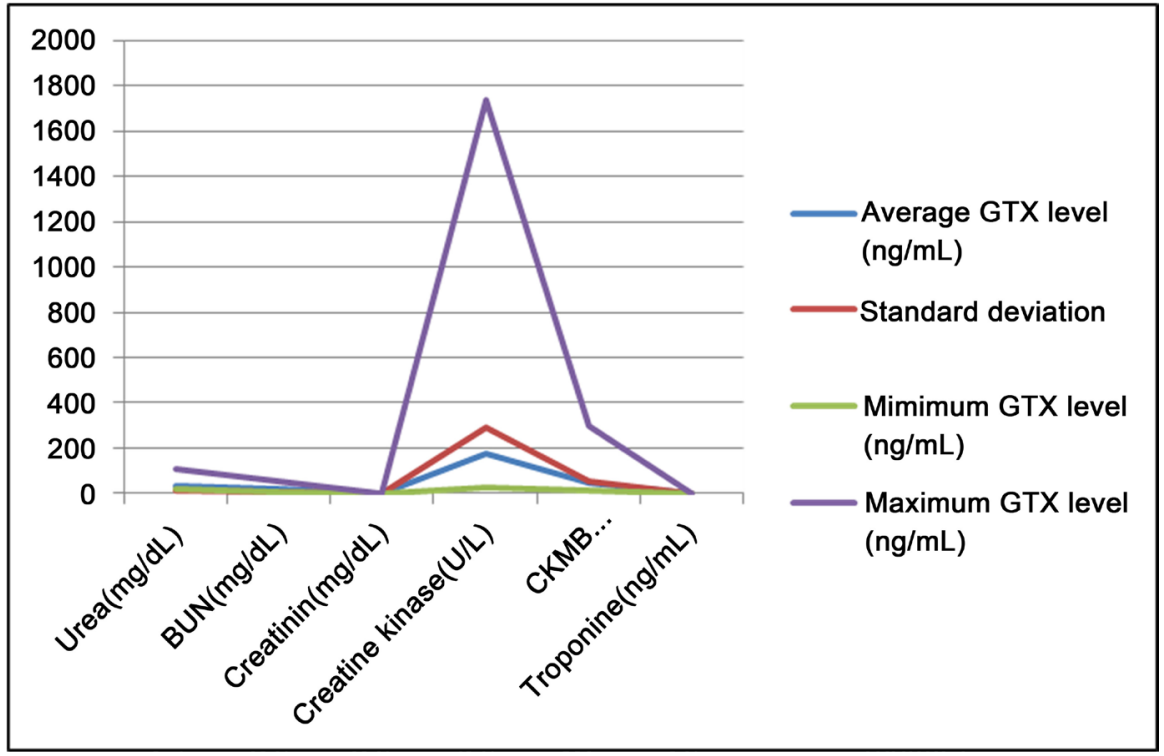

Figure 1. Renal function tests and cardiac biomarkers in the case group.

The first signs of poisoning are increasing of salivation, nausea, vomiting, paresthaesia around the mouth and extremities. Typical poisoning findings are gastrointestinal system irritation findings, life-threatening bradycardia and dizziness caused by hypotension and central nervous system effects. GTX poisoning should be suspected if there is one or more of these clinical findings and honey eating story.

In the presence of acute, life-threatening clinical findings such as bradycardia, vomiting, diarrhea and delirium, the honey eating story must be questioned. Symptoms in cases of mild GTX poisoning resolve spontaneously within 12 - 24 hours without requiring any treatment [16]. Hypotension resulting from vasodilatation due to sodium channel blockage is eliminated by infusion of $0.9 \%$ sodium chloride IV. IV atropine is applied to patients who develop bradycardia [5].

Similar to our study, the relationship between GTX level and symptoms was investigated in the study conducted by Aygun et al. [22]. Although there was no correlation between the amount of honey and the level of GTX and symptoms, the findings were the fastest in this patient and the GTX was the highest in this patient. In our study, there was no significant correlation between the amount of honey taken and the measured GTX level and symptoms.

Bostan et al. retrospectively investigated sex, most frequent complaints and EKG findings of patients who were exposed to mad honey poisoning [23]. According to this study, the most common complaints of the patients were nausea-vomiting (81\%) and dizziness (78\%). The most common ECG findings were sinus bradycardia. Gündüz et al. examined 47 patients who applied to the three major centers in the Black Sea region between January and October 2007 [24]. They found that the most common complaints of the patients were dizziness, nausea and vomiting. The most common EKG finding in the study at the time of admission to the hospital was sinus bradycardia in the patient, nodal rhythm in 
6 patients and AV complete block in one patient. Yilmaz et al. studied 66 patients who were exposed to mad honey poisoning [13]. Blurred vision, nausea, vomiting, syncope, and increased salivation are also among the complaints of the patients when dizziness and weakness are present in all of the patients. The most common EKG finding in the study of Yilmaz et al. is sinus bradycardia.

In our study, 36 patients with grayanotoxin poisoning were evaluated. The most common complaints were nausea (75\%) and dizziness (69\%). Other complaints include fatigue, vomiting, burning in the throat, and abdominal pain. When hospital entrance EKGs of the study group are examined; among 36 patients; 19 patients had sinus bradycardia, 15 patients had normal sinus rhythm, one patient had anterior myocardial infarction (MI), and one patient had Ventricular Tachycardia (VT).

When electrocardiographic studies and twelve different case series were examined, no MI or VT cases were found. Our work differs in this respect. In the literature, it is known that hypotension and bradycardia, which are the result of mad honey ingestion, may cause coronary perfusion and myocardial infarction. However, no myocardial infarction due to GTX poisoning has been encountered until our study [15].

Symptoms usually occur within 1 to 3 hours after ingestion of mad honey when the onset duration of symptoms and the amount to cause in GTX poisoning is evaluated. In their case, Demircan et al. emphasized that the symptoms started within 0.5 to 1 hour after ingesting honey [25]. In our study, the symptoms occurred after a minimum of 1 hour and a maximum of 8 hours after ingesting mad honey. Patient who developed symptoms within an average of 3 hours applied to emergency services. The duration of the emergence symptoms in our study is similar to the previous studies. Symptoms of toxicity can occur with little ingestion of honey in poisonings caused by mad honey ingestion. It has been shown in the literature that intoxication can occur even with a tea spoon of honey [1]. However, in different studies it has been reported that symptoms may start with different amounts of honey (5 - $180 \mathrm{~g})$ ingestion [1] [26]. In our study, there are patients who are found to be poisoned with a tea spoon of mad honey. However, in our study, there was no relationship between the amount of honey taken and the onset of symptoms. Here again, there was no relationship between the amount of honey taken and the duration of symptoms since there was no correlation between the amount of honey and the toxin contained in the honey. It is thought that the reason for this is not the amount taken alone, but genetic factors may have a role, too. It is also thought that the amount of toxin contained in honey varies depending on the type of the flower that the bee was fed on and the season.

There are only a few studies in the literature evaluating the purpose of taking honey in grayanotoxin poisoning cases. The first of these is the work of Yaylaci et al. done with 82 patients [27] [28]. In this work by Yaylaci et al., it was observed that, besides nutritional consumption of mad honey, 18 patients were found to use it for gastrointestinal complaints, 11 patients for hypertension, one 
patient for diabetes and one patient for cancer prevention. It was also determined that there was no use in any patient as a sexual performance enhancer [22]. In our study, 33 patients from 36 patients who had mad honey stated that they took it for healing purposes, because they were good for them as an alternative medicine and the other 3 patients only ate mad honey as they love it just for nutritional consumption. As in other studies, no patient in our study has stated that they use sexual performance as an enhancer.

In our study, the relationship between renal function tests (urea, BUN, creatinine) and cardiac biomarkers (troponin, control troponin) was also investigated in cases of GTX poisoning. No such research has been found in the previous publications. Mad honey poisoning may cause kidney dysfunction as this poisoning also causes hypotension accompanied with significant bradycardia. As a result, kidney troponin exacerbation may also be impaired, and even if cardiac damage does not develop, increasing of troponin level may be seen. Therefore, the increasing of troponin level in these patients should be carefully evaluated together with other parameters (EKG and echocardiographic findings, etc.).

When the duration of observation in GTX poisonings was evaluated, no consensus was reached on how long patients who applied for GTX poisoning would be kept under observation. In a study conducted by Gunduz et al., GTX poisoning cases were reported to be safely discharged 2 to 6 hours after cardiac monitoring [4]. Yaylaci et al. followed the patients in an average of $27 \pm 7$ hours and emphasized the length of follow-up [28]. In our study, all patients were followed under cardiac monitoring for 6 hours beginning from the time they applied to the hospital. At the end of the six-hour follow-up, all patients were discharged safely except for one patient. One patient was admitted to the cardiology department for anterior MI. Our follow-up is similar to the study done by Gündüz et al, although it is a short duration compared to the study of Yaylaci et al.

When the treatment and prognosis of GTX poisonings were evaluated, there were no mortal cases due to GTX poisoning in the literature. In cases of GTX poisoning, although symptoms are serious and dangerous, most cardiac monitoring, fluid therapy, and intravenous atropine therapy are sufficient to restore symptoms [22] [28]. In one study, normal sinus rhythm and normal blood pressure values were obtained after an average of $0.78 \mathrm{mg}$ of atropine and $841 \pm$ $332 \mathrm{~mL}$ of $0.9 \%$ isotonic fluid. In the same study, there were no patients who need intensive care and the temporary cardiac pacemaker application [22]. In our study, normal sinus rhythm and normal blood pressure values were obtained in patients with atropine and isotonic fluid treatment. No patient required intensive care and temporary cardiac pacemaker application. We didn't have mortal case.

\section{Constraints}

At the beginning of the constraints of our work is the number of patients included in the study. In a study where more patients can be involved, it may be expected to achieve better results. In order to increase the number of patients to 
be studied, the study can be done in a multi-centered manner.

\section{Conclusions}

Our study is a rare study that investigates the GTX level when the patient group and examined values are taken into consideration. GTX levels were found to be statistically higher in patients who applied to the emergency department due to mad honey poisoning and included in the study. There was no significant difference in symptoms, amount of honey and GTX levels in patients ingesting mad honey. In patients ingesting mad honey, a positive relationship was found between urea and BUN, and troponin and control troponin. There was a positive correlation between creatinine and control troponin. There was no significant difference in the symptoms of patients who ingested mad honey and how long before honey was taken.

When patients apply to the emergency services with the symptoms of blood pressure and heart rate drops, emergency physicians must question the story of eating mad honey. Symptoms should not be related to the amount of honey taken and it should not be forgotten that a very small amount of honey may cause serious problems. It should not be forgotten that the toxic effect of honey is also dependent on the plant species and season in which the bee is fed. For this reason, further research is needed to address the limitations of our work to further clarify the symptoms and GTX relationship.

We think that the toxin in mad honey can be used to develop a drug that can be used in patients with tachycardia accompanied by hypertension after passing through all phases of drug development.

\section{References}

[1] Viccellio, P. (1993) Systemic Poisonous Plant Intoxication. Handbook of MedicalToxicology. Washington Library of Congress Cataloging, 718.

[2] Koca, I. and Koca, F.A. (2007) Poisoningby Mad Honey: A Brief Review. Food and Chemical Toxicology, 45, 1315-1318.

[3] Maejima, H., Kinoshita, E., Seyama, I. and Yamaoka, K. (2003) Distinct Sites Regulating Grayanotoxin Binding and Unbinding to D4S6 of Nav1.4 Sodium Channel as Revealed by Improved Estimation of Toxin Sensitivity. The Journal of Biological Chemistry, 278, 9464-9471. https://doi.org/10.1074/jbc.M212133200

[4] Gunduz, A., Turedi, S., Russell, R.M. and Ayaz, F.A. (2008) Clinical Review of Grayanotoxin/Mad Honey Poisoning Past and Present. Clinical Toxicology, 46, 437-442. https://doi.org/10.1080/15563650701666306

[5] Başgül, A. (2003) Deli Bal Zehirlenmesi. Journal of Critical Care, 3, 33-36.

[6] Xenophon: Anabasis, or March Up Country. Fordham University Website. http://www.fordham.edu/halsall/ancient/xenophon-anabasis.html\#

[7] Gökçel, T. Xenophon: Anabasis, Onbinlerin Dönüşü. Social Editionsecondpress, Sena Offset, 143-144.

[8] Kebler, L.F. (1896) Poisonous Honey. American Pharmacists Association, 44, 167174.

[9] Biberoglu, S., Biberoglu, K. and Komsuoglu, B. (1988) Mad Honey. JAMA, 259, 
1943. https://doi.org/10.1001/jama.1988.03720130021010

[10] Onat, F.Y.,Yegen, B.C. and Lawrence, R. (1991) Mad Honey Poisoning in Man and Rat. Reviews on Environmental Health, 9, 3-9.

[11] Ozhan, H., Akdemir, R. and Yazici, M. (2004) Cardiac Emergencies Caused by Honey Ingestion: A Single Centre Experience. Emergency Medicine Journal, 21, 742-744. https://doi.org/10.1136/emj.2003.009324

[12] Durmus, I., Türedi, S., Gündüz, A. and Öztürk, S. (2007) Mad Honey PoisoningRelated Asystole. Emergency Medicine Journal, 24, 592-593.

[13] Yilmaz, O., Eser, M., Sahiner, A., Altintop, L. and Yesildag, O. (2006) Hypotension, Bradycardia and Syncope Caused by Honey Poisoning. Resuscitation, 68, 405-408. https://doi.org/10.1016/j.resuscitation.2005.07.014

[14] Yavuz, H., Ozel, A., Akkus, I. and Erkul, I. (1991) Honey Poisoning in Turkey. The Lancet, 337, 789-790. https://doi.org/10.1016/0140-6736(91)91405-J

[15] Yildirim, N., Aydin, M., Cam, F. and Celik, O. (2008) Clinical Presentation of NonST-Segment Elevation Myocardial Infarction in the Course of Intoxication with Mad Honey. American Journal of Emergency Medicine, 26, 108.e1-108.e2.

[16] Eddleston, M., Buckley, N.A., Eyerand, P. and Dawson, A.H. (2008) Medical Management of Acute Organophosphorus Pesticide Self-Poisoning. The Lancet, 371, 597-607.

[17] Geroulanos, S., Attinger, B. and Çakmakçi, M. (1992) Honey-Induced Poisoning. Schweizerische Rundschau Fur Medizin Praxis, 81, 535-540.

[18] Çalangu, S. (1995) Emergency Internal Medicine. Arts Offset, Istanbul, 613.

[19] Dökmeci, I. (2001) Food Poisoning. Toxicology/Poisonings Diagnosis and Therapy. Nobel Medicine Bookstore, Istanbul, 563.

[20] Akpir, K. and Dilmener, M. (1984) Drug, Food and Gas Poisoning. ITF Publication

[21] Gunduz, A., Turedi, S., Uzun, H. and Topbas, M. (2006) Mad Honey Poisoning. American Journal of Emergency Medicine, 24, 595-598. https://doi.org/10.1016/j.ajem.2006.01.022

[22] Aygun, A., Gündüz, A., Türedi, S., Turkmen, S., Karaca, Y., Ayaz, F.A., Ahn, S.Y. and Kim, S. (2015) Examination Using LC-MS/MS Determination of Grayanotoxin Levels in Blood, Urine, and Honey Consumed by Patients Presenting to the Emergency Department with Mad Honey İntoxication and Relations with Clinical Data: A Preliminary Study. Annals of Saudi Medicine, 35, 161-164.

[23] Bostan, M., Bostan, H., Kaya, A.O., Bilir, O., Satiroglu, O., Kazdal, H., Karadag, Z. and Bozkurt, E. (2009) Clinical Events in Mad Honey Poisoning: A Single Centre Experience. Bulletin of Environmental Contamination and Toxicology, 84, 19-22. https://doi.org/10.1007/s00128-009-9906-2

[24] Gunduz, A., Meriç, E.S., Baydin, A., Topbaş, M., Uzun, H., Türedi, S. and Kalkan, A. (2009) Does Mad Honey Poisoning Require Hospital Admission? American Journal of Emergency Medicine, 27, 424-427. https://doi.org/10.1016/j.ajem.2008.03.021

[25] Demircan, A., Keleş, A., Bildik, F., Aygencel, G., Doğan, O.N. and Gómez, H.F. (2009) Mad Honey Sex: Therapeutic Misadventures from an Ancient Biological Weapon. Annals of Emergency Medicine, 54, 824-829. https://doi.org/10.1016/j.annemergmed.2009.06.010

[26] Olson, K. (1990) Specific Poisons and Drugs: Diagnosis and Treatment. Poisoning \& Drug Overdose. Connecticut Apleton \& Lange Pub, 246.

[27] Yaylaci, S., Kocayigit, I., Aydin, E., Osken, A., Genc, A.B., Cakar, M.A. and Tamer, 
A. (2014) Clinical and Laboratory Findings in Mad Honey Poisoning: A Single Center Experience. Nigerian Journal of Clinical Practice, 17, 589-593.

https://doi.org/10.4103/1119-3077.141424

[28] Yaylaci, S., Ayyildiz, O., Aydin, E., et al. (2015) Is There a Difference in Mad Honey Poisoning between Geriatric and Non-Geriatric Patient Groups? European Review for Medical and Pharmacological Sciences, 19, 4647-4653.

Submit or recommend next manuscript to SCIRP and we will provide best service for you:

Accepting pre-submission inquiries through Email, Facebook, LinkedIn, Twitter, etc. A wide selection of journals (inclusive of 9 subjects, more than 200 journals)

Providing 24-hour high-quality service

User-friendly online submission system

Fair and swift peer-review system

Efficient typesetting and proofreading procedure

Display of the result of downloads and visits, as well as the number of cited articles Maximum dissemination of your research work

Submit your manuscript at: http://papersubmission.scirp.org/

Or contact ojem@scirp.org 